\title{
SISTEM PAKAR MENDIAGNOSA PENYAKIT KAKI GAJAH MENGGUNAKAN METODE CERTAINTY FACTOR
}

\author{
Nelly Astuti Hasibuan', Hery Sunandar ${ }^{2}$, Senanti Alas ${ }^{3}$, Suginam ${ }^{4}$ \\ 1,2,4 Dosen Tetap STMIK Budi Darma \\ ${ }^{3}$ Mahasiswa Teknik Informatika, STMIK Budi Darma \\ 1, 2, 3, 4 Jl. Sisingamangaraja No.338 Simpang Limun Medan
}

\begin{abstract}
Elephant foot disease or filariasis is a contagious disease caused by filarial worms that are transmitted through the type of mosquito. This disease is chronic and if not get treatment will result in permanent disability in the form of leg enlargement, genitals both women and men. Elephant foot disease is generally detected through blood microcopy examination. Until now it is still felt because microfilaria only appear in the blood at night for several hours (nocturnal perioicity). In addition, various methods of examination are also performed to diagnose elephantiasis diseases such as those known as membrane crawl, knott concentration method and deposition technique. This study identifies elephantiasis and its causes, and applies certainty factor methods and designs expert systems to diagnose elephantiasis. To diagnose elephantiasis by using certainty factor method. Patients will be given questions to obtain probable values and then the values obtained will be solved by certainty factor formulation, so that the diagnosis and percentage is likely to develop elephantiasis.
\end{abstract}

Keywords: Elephant Foot, Certainty Factor, and Expert System

\begin{abstract}
Abstrak
Penyakit kaki gajah atau filariasis adalah penyakit menular yang disebabakan oleh cacing filarial yang ditularkan melalui jenis nyamuk. Penyakit ini bersifat kronis dan bila tidak mendapatkan pengobatan akan mengakibatkan cacat menetap berupa pembesaran kaki, alat kelamin baik perempuan maupun laki-laki. Penyakit kaki gajah ini umumnya terdeteksi melalui pemeriksaan mikrokopis darah. Sampai saat ini hal tersebut masih dirasakan karena microfilaria hanya muncul didalam darah pada waktu malam hari selama beberapa jam (nocturnal perioicity). Selain itu berbagai metode pemeriksaan juga dilakukan untuk mendiagnosa penyakit kaki gajah diantaranya ialah dengan yang dikenal sebagai penjaringan membrane, metode konsentrasi knott dan teknik pengendapan. Penelitian ini mengidentifikasi penyakit kaki gajah dan penyebabnya, serta menerapkan metode certainty factor dan merancang sistem pakar untuk mendiagnosa penyakit kaki gajah. Untuk mendiagnosa penyakit kaki gajah dengan menggunakan metode certainty factor. Pasien akan diberikan pertanyaan-pertanyaan untuk mendapatkan nilai kemungkinan dan kemudian nilai yang didapat akan diselesaikan dengan rumusan
\end{abstract}


certainty factor, sehingga hasil diagnosa serta persentasi kemungkinan mengalami penyakit kaki gajah.

Kata Kunci: Kaki Gajah, Certainty Factor, dan Sistem Pakar

\section{PENDAHULUAN}

Penyakit kaki gajah (filariasis) adalah penyakit yang ditandai dengan gejala seperti pembengkakkan bagian badan yang terjadi secara perlahan-lahan menyebabkan kaki terlihat seperti gajah. Penyakit ini disebabkan karena sejenis cacing benang putih yang ditularkan melalui nyamuk. Gejala dari penyakit kaki gajah (filariasis) ini adalah biasanya terjadi pada masa anak-anak, dimana dalam waktu yang lebih lama sekitar bertahun-tahun kemudian akan terasa perkembangannya yang terjadi. Penyakit ini bersifat kronis dan bila tidak mendapatkan pengobatan akan mengakibatan cacat menetap berupa pembesaran kaki, dan alat kelamin baik perempun maupun laki-laki.

Beberapa gejalanya ialah demam yang terjadi secara berulang sekitar 3-5 hari, demam ini kemudian akan hilang jika dibawa istirahat yang cukup dan akan muncul lagi jika melakukan aktivitas dengan berlebihan. Pembengkakan yang terjadi pada kelenjar getah bening, didaerah sekitar lipatan paha, ketiak dan juga nampak berwarna seperti kemerahan. Radang saluran kelenjar getah bening yang rasanya seperti panas dan sakit kemudian akan menjalar dari arah pangkal kaki atau juga pada pangkal lengan menuju ke arah ujung (retrogade lumphangitis)[1].

Umumnya, filariasis akan bersifat mikrofilaremia subklinis. Kebanyakan penderita ini merupakan masyarakat perdesaan hingga sama sekali tidak terdeteksi oleh pranata kesehatan yang berada di lingkungan tersebut. Jika telah parah dan kronis dapat menimbulkan hidrokel, acute adenolymphangytis atau ADL (activity daily living). Jika ada satu atau dua orang yang skrotumnya tiba-tiba sudah besar, kemungkinan sudah banyak sekali laki-laki yang terinfeksi parasit ini. Meski demikian, jika ingin mendeteksi secara dini, dalam fase subklinis penderita filariasis bancrofti akan mengalami hematuria.

Sistem pakar adalah sistem yang mampu menirukan penalaran seorang pakar komputer dapat menyelesaikan masalah yang seperti biasa dilakukan oleh para ahli. Pengetahuan yang disimpan di dalam sistem pakar umumnya diambil dari seorang manusia yang pakar dalam masalah tersebut[2][3]. Peran penting seorang pakar dapat digantikan oleh program komputer yang pada prinsipnya kerjanya untuk memberikan solusi yang pasti seperti yang biasa dilakukan oleh pakar. Sistem pakar biasanya digunakan untuk konsultasi, analisa, diagnosa, dan membantu mengambil keputusan[4].

\section{METODOLOGI PENELITIAN}

\subsection{Sistem Pakar}

Sistem pakar adalah salah satu cabang Artificial Intellegence yang membuat penggunaan secara luas knowledge yang khusus untuk penyelesaian masalah tingkat manusia yang pakar. Seorang pakar adalah orang yang mempunyai keahlian dalam bidang tertentu, yaitu pakar yang mempunyai knowledge atau 
kemampuan khusus yang orang lain tidak mengetahui atau mampu dalam bidang yang dimilikinya[5][6].

Sistem pakar ini juga akan dapat membantu aktivitas para pakar sebagai asisten yang berpengalaman dan mengkombinasikan kaidah-kaidah penarikan kesimpulan (inference rules) dengan basis pengetahuan tertentu yang diberikan oleh satu atau lebih pakar dalam bidang tertentu[7]. Kombinasi dari kedua hal tersebut disimpan dalam komputer, yang selanjutnya digunakan dalam proses pengambilan keputusan untuk penyelesaian masalah tertentu.

\subsection{Kaki Gajah atau Filariasis}

Penyakit kaki gajah atau filariasis adalah penyakit menular yang disebabakan oleh cacing filarial yang ditularkan melalui jenis nyamuk. Penyakit ini bersifat kronis dan bila tidak mendapatkan pengobatan akan mengakibatkan cacat menetap berupa pembesaran kaki, alat kelamin baik perempuan maupun laki-laki [1].

Penyakit kaki gajah ini umumnya terdeteksi melalui pemeriksaan mikrokopis darah. Sampai saat ini hal tersebut masih dirasakan karn microfilaria hanya muncul didalam darah pada waktu malam hari selama beberapa jam (nocturnal perioicity). Selain itu berbagai metode pemeriksaan juga dilakukan untuk mendiagnosa penyakit kaki gajah diantaranya ialah dengan yang dikenal sebagai penjaringan membrane, metode konsentrasi knott dan teknik pengendapan. Metode pemeriksaan yang lebih mendekati kearah diagnosa yang dilakukan oleh pihak WHO (wordl health organization) adalah jalanpemeriksaan system "Tes kartu", hai ini sangatlah sederhana dan peka untuk mendeteksi penyebar parasit (larva), yaitu dengan cara mengambil sample darah dengan system tusukan jari droplets diwaktu kapanpun, tidak harus dimalam hari.

\subsection{Metode Certainty Factor}

Faktor kepastian (certainty factor) diusulkan oleh Shortliffe dan Buchanan pada 1975 untuk mengakomadasikan ketidakpastian pemikiran (inexact reasoning) seorang pakar. Seorang pakar, (misalnya dokter) sering kali menganalisis informasi yang ada dengan ungkapan seperti misalnya : mungkin, kemungkinan, besar, hampir pasti. Untuk mengakomodasi hal ini dengan menggunakan certainty factor (CF) guna menggambarkan tingkat keyakinan pakar terhadap masalah yang dihadapi. Secara umum, rule direpresentasikan dalam bentuk sebagai berikut [8] :

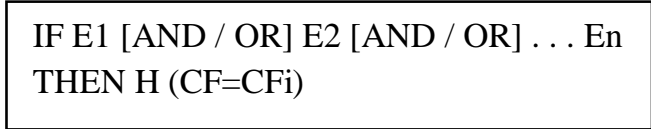

\section{Dimana :}

E1...En : fakta-fakta (evidence) yang ada

$\mathrm{H} \quad$ : hipotesa atau konklusi yang dihasilkan

CF : tingkat keyakinan (certainty factor) terjadinya hipotesa akibat adanya fakta-fakta 
Definisi menurut David McAllister, certainty factor adalah suatu metode untuk membuktikan apakah suatu fakta itu pasti ataukah tidak pasti yang berbentuk metric yang biasanya digunakan dalam sistem pakar. Metode ini sangat cocok untuk sistem pakar yang mendiagnosis sesuatu yang belum pasti.

Metode certainty factor ini hanya bisa mengolah 2 bobot dalam sekali perhitungan. Untuk bobot yang lebih dari 2 banyaknya, untuk melakukan perhitungan tidak terjadi masalah apabila bobot yang dihitung teracak, artinya tidak ada aturan untuk mengkombinasikan bobotnya, karena untuk kombinasi seperti apapun hasilnya akan tetap sama. Misalnya, untuk mengetahui apakah seorang pasien tersebut menderita penyakit jantung atau tidak, dilihat dari hasil perhitungan bobot setelah semua keluhan-keluhan diinputkan dan semua bobot dihitung dengan menggunakan metode certainty factor. Pasien yang divonis mengidap penyakit jantung adalah pasien yang memiliki bobot mendekati +1 dengan keluhan-keluhan yang dimiliki mengarah kepada penyakit jantung. Sedangkan pasien yang mempunyai bobot mendekati -1 adalah pasien yang dianggap tidak mengidap penyakit jantung, serta pasien yang memiliki bobot sama dengan 0 diagnosisnya tidak diketahui atau unknown atau bisa disebut dengan netral.

$\mathrm{CF}(\mathrm{H}, \mathrm{E})=\mathrm{MB}(\mathrm{H}, \mathrm{E})-\mathrm{MD}(\mathrm{H}, \mathrm{E})$

Dimana :

$\mathrm{CF}(\mathrm{H}, \mathrm{E})$ : Certainty Factor dari hipotesis $\mathrm{H}$ yang dipengaruhi oleh gejala (evidence) E. Besarnya CF berkisar antara -1 sampai 1 . Nilai -1 menunjukkan ketidakpercayaan mutlak sedangkan nilai 1 menunjukkan kepercayaan mutlak.

MB (H, E): ukuran kenaikan kepercayaan (measure of increased belief) terhadap hipotesis $\mathrm{H}$ yang dipengaruhi oleh gejala E.

MD (H, E): ukuran kenaikan ketidakpercayaan (measure of increased disbelief) terhadap hipotesis $\mathrm{H}$ yang dipengaruhi oleh gejala E.Bentuk dasar rumus certainty factor, adalah sebuah aturan JIKA E MAKA H seperti ditunjukkan oleh persamaan 2 berikut:

$\mathrm{CF}(\mathrm{H}, \mathrm{e})=\mathrm{CF}(\mathrm{E}, \mathrm{e}) * \mathrm{CF}(\mathrm{H}, \mathrm{E})$

Dimana :

$\mathrm{CF}(\mathrm{H}, \mathrm{e}) \quad$ : certainty factor hipotesis yang dipengaruhi oleh evidence e.

$\mathrm{CF}(\mathrm{E}, \mathrm{e}) \quad$ : certainty factor evidence E yang dipengaruhi oleh evidence e.

$\mathrm{CF}(\mathrm{H}, \mathrm{E}) \quad$ : certainty factor hipotesis dengan asumsi evidence diketahui dengan pasti, yaitu ketika $\mathrm{CF}(\mathrm{E}, \mathrm{e})=1$. Jika semua evidence pada antecedent diketahui dengan pasti maka persamaannya akan menjadi:

$\mathrm{CF}(\mathrm{E}, \mathrm{e})=\mathrm{CF}(\mathrm{H}, \mathrm{E})$ 
Dalam aplikasinya, $\mathrm{CF}(\mathrm{H}, \mathrm{E})$ merupakan nilai kepastian yang diberikan oleh pakar terhadap suatu aturan, sedangkan $\mathrm{CF}(\mathrm{E}, \mathrm{e})$ merupakan nilai kerpercayaan yang diberikan oleh pengguna terhadap gejala yang dialaminya.

Sebagai contoh, berikut ini adalah sebuah aturan dengan CF yang diberikan oleh seorang pakar:

JIKA batuk

DAN demam

DAN sakit kepala

DAN bersin-bersin

MAKA influensa, CF: 0,7

Diantara kondisi yang terjadi adalah terdapat beberapa antensenden (dalam rule yang berbeda) dengan satu konsekuen yang sama. Dalam kasus ini, kita harus mengagregasikan nilai CF keseluruhan dari setiap kondisi yang ada.

Berikut Formula yang digunakan :

$\mathrm{CFc}\left(\mathrm{CF}_{1}, \mathrm{CF}_{2}\right)=\mathrm{CF}_{1}+\mathrm{CF}_{2}\left(1-\mathrm{CF}_{1}\right)$ : jika $\mathrm{CF}_{1}$ dan $\mathrm{Cf}_{2}$ keduanya positif

$\mathrm{CFc}\left(\mathrm{CF}_{1}, \mathrm{CF}_{2}\right)=\mathrm{CF}_{1}+\mathrm{CF}_{2}\left(1+\mathrm{CF}_{1}\right):$ jika $\mathrm{CF}_{1}$ dan $\mathrm{Cf}_{2}$ keduanya negatif

$\mathrm{CFc}\left(\mathrm{CF}_{1}, \mathrm{CF}_{2}\right)=\left\{\mathrm{CF}_{1}+\mathrm{CF}_{2}\right\} /\left(1-\min \left\{\left|\mathrm{CF}_{1}\right|,\left|\mathrm{CF}_{2}\right|\right\}\right)$ : jika salah satu negatif

Certainty factor untuk hasil akhir persentase $:$ Persentase keyakinan $=$ Cfcombine $*$ $100 \%$

\section{HASIL dan PEMBAHASAN}

\subsection{Analisa Diagnosa Penyakit Kaki Gajah (Filariasis)}

Dalam tahapan ini dilakukan pencarian dan pengumpulan data serta pengetahuan yang diperoleh oleh sistem pakar. Sehingga pada akhirnya analisa yang didapat harus berupa sebuah sistem yang strukturnya dapat didefinisikan dengan baik dan jelas. Sistem yang dibangun untuk menentukan gejala penyakit kaki gajah pada masyarat dengan cara manual, yaitu dengan cara melakukan konsultasi antar dokter terhadap pasiennya. Konsultasi yang dilakukan dengan dokter atau pakar adalah untuk memperoleh gejala-gejala yang diderita pasien, kemudian dari gejala yang telah diperoleh dihasilkan diagnosa berupa suatu penyakit.

Tahapan analisis terhadap suatu sistem dilakukan sebelum tahapan perancangan dilakukan. Tujuan diterapkannya analisis terhadap suatu sistem adalah untuk mengetahui alasan mengapa sistem tersebut diperlukan, sehingga fungsi yang terdapat didalam sistem tersebut bekerja secara optimal. Salah satu unsur pokok yang harus dipertimbangkan dalam tahapan analisis sistem ini yaitu masalah perangkat lunak, karena perangat lunak yang digunakan haruslah sesuai dengan masalah yang akan diselesaikan. 
Dalam mengekspresikan derajat kepastian, certainty factor untuk mengansumsikan derajat kepastian seorang pakar terhadap suatu data. Konsep ini kemudian diformulasikan dalam rumusan dasar sebagai berikut :

$\mathrm{CF}[\mathrm{H}, \mathrm{E}]=\mathrm{MB}[\mathrm{H}, \mathrm{E}]-\mathrm{MD}[\mathrm{H}, \mathrm{E}]$

$\mathrm{CF}[\mathrm{H}, \mathrm{E}]=\mathrm{CF}[\mathrm{H}] * \mathrm{CF}[\mathrm{E}]$

Cfcombine CF[H,E] 1,2 + CF[H,E] $2 *$ [1-CF[H,E] 1]

Cfcombine CF[H,E] old,3 = CF[H,E] old + CF[H,E] 3 * [1-CF[H,E] old $]$

Contoh kasus :

Kaidah produksi atau aturan rule yang berkaitan dengan kaki gajah adalah sebagai berikut:

Kaidah

IF Demam berulang-ulang selama 3-5 hari

AND Pembengkakan kelenjar getah bening

AND Panas dan sakit radang saluran kelenjar getah bening

AND Filarial abses

AND Pembesaran tungkai

AND Pembesaran lengan

AND Pembesaran buah dada

AND Pembesaran buah zakar

THEN Filariasis atau Kaki gajah

Langkah pertama, pakar menentukan CF untuk masing-masing gejala sebagai berikut :

CFpakar (Demam berulang-ulang selama 3-5 hari) $\quad=0.4$

CFpakar (Pembengkakan kelenjar getah bening) $\quad=0.6$

CFpakar (Panas dan sakit radang saluran kelenjar getah bening) $\quad=0.6$

CFpakar (Filarial abses)

$=0.6$

CFpakar (Pembesaran tungkai)

$=0.8$

CFpakar (Pembesaran lengan)

$=0.8$

CFpakar (Pembesaran buah dada)

$=0.8$

CFpakar (Pembesaran buah zakar)

$=0.8$

Misalkan user memilih jawaban sebagai berikut :

Demam berulang-ulang selama 3-5 hari

$=0.2$

Pembengkakan kelenjar getah bening

$=0.4$

Panas dan sakit radang saluran kelenjar getah bening

$=0.4$

Filarial abses

$=0.4$

Pembesaran tungkai

$=0.6$

Pembesaran lengan

$=0.6$

Pembesaran buah dada

$=0.6$

Pembesaran buah zakar

$=0.6$ 
Kaidah tersebut kemudian dihitung nilai Cfpakarnya dengan mengalikan Cfuser dengan CF menjadi :

$$
\begin{aligned}
\mathrm{CF}[\mathrm{H}, \mathrm{E}] 1 & =\mathrm{CF}[\mathrm{H}] 1^{*} \mathrm{CF}[\mathrm{E}] 1 \\
& =0.4^{*} 0.2 \\
& =0.08 \\
\mathrm{CF}[\mathrm{H}, \mathrm{E}] 2 & =\mathrm{CF}[\mathrm{H}] 2^{*} \mathrm{CF}[\mathrm{E}] 2 \\
& =0.6^{*} 0.4 \\
& =0.24 \\
\mathrm{CF}[\mathrm{H}, \mathrm{E}] 3 & =\mathrm{CF}[\mathrm{H}] 3^{*} \mathrm{CF}[\mathrm{E}] 3 \\
& =0.6^{*} 0.4 \\
& =0.24 \\
\mathrm{CF}[\mathrm{H}, \mathrm{E}] 4 & =\mathrm{CF}[\mathrm{H}] 4^{*} \mathrm{CF}[\mathrm{E}] 4 \\
& =0.6^{*} 0.4 \\
& =0.24 \\
\mathrm{CF}[\mathrm{H}, \mathrm{E}] 5 & =\mathrm{CF}[\mathrm{H}] 5^{*} \mathrm{CF}[\mathrm{E}] 5 \\
& =0.8^{*} 0.6 \\
& =0.48 \\
\mathrm{CF}[\mathrm{H}, \mathrm{E}] 6 & =\mathrm{CF}[\mathrm{H}] 6^{*} \mathrm{CF}[\mathrm{E}] 6 \\
& =0.8^{*} 0.6 \\
& =0.48 \\
\mathrm{CF}[\mathrm{H}, \mathrm{E}] 7 & =\mathrm{CF}[\mathrm{H}] 7^{*} \mathrm{CF}[\mathrm{E}] 7 \\
& =0.8^{*} 0.6 \\
& =0.48 \\
\mathrm{CF}[\mathrm{H}, \mathrm{E}] 8 & =\mathrm{CF}[\mathrm{H}] 8^{*} \mathrm{CF}[\mathrm{E}] 8 \\
& =0.8^{*} 0.6 \\
& =0.48
\end{aligned}
$$

Langkah yang terakhir adalah mengkombinasikan nilai $\mathrm{CF}$ dari kaidah. Berikut adalah kombinasi $\mathrm{CF}[\mathrm{H}, \mathrm{E}]$ dengan $\mathrm{CF}[\mathrm{H}, \mathrm{E}]$ :

CFcombine $\mathrm{CF}[\mathrm{H}, \mathrm{E}] 1,2$

$=\mathrm{CF}[\mathrm{H}, \mathrm{E}] 1+\mathrm{CF}[\mathrm{H}, \mathrm{E}] 2 *(1-\mathrm{CF}[\mathrm{H}, \mathrm{E}] 1)$

$=0.08+0.24(1-0.08)$

$=0.08+0.24(0.92)$

$=0.08+0.22$

$=0.3_{\text {old }}$

CFcombine $\mathrm{CF}[\mathrm{H}, \mathrm{E}]$ old,3

$=\mathrm{CF}[\mathrm{H}, \mathrm{E}]$ old $+\mathrm{CF}[\mathrm{H}, \mathrm{E}] 3 *(1-\mathrm{CF}[\mathrm{H}, \mathrm{E}]$ old $)$

$=0.3+0.24(1-0.3)$

$=0.3+0.24(0.7)$

$=0.3+0.16$

$=0.46$ old 2

CFcombine CF[H,E]old2,4 
$=\mathrm{CF}[\mathrm{H}, \mathrm{E}]$ old $2+\mathrm{CF}[\mathrm{H}, \mathrm{E}] 4 *(1-\mathrm{CF}[\mathrm{H}, \mathrm{E}]$ old 2$)$

$=0.46+0.24(1-0.46)$

$=0.46+0.24(0.54)$

$=0.46+0.12$

$=0.58_{\text {old } 3}$

CFcombine $\mathrm{CF}[\mathrm{H}, \mathrm{E}] \mathrm{old} 3,5$

$=\mathrm{CF}[\mathrm{H}, \mathrm{E}]$ old $3+\mathrm{CF}[\mathrm{H}, \mathrm{E}] 5 *(1-\mathrm{CF}[\mathrm{H}, \mathrm{E}]$ old 3$)$

$=0.58+0.48(1-0.58)$

$=0.58+0.48(0.42)$

$=0.58+0.20$

$=0.78$ old 4

CFcombine $\mathrm{CF}[\mathrm{H}, \mathrm{E}]$ old 4,6

$=\mathrm{CF}[\mathrm{H}, \mathrm{E}]$ old $4+\mathrm{CF}[\mathrm{H}, \mathrm{E}] 6 *(1-\mathrm{CF}[\mathrm{H}, \mathrm{E}]$ old 4$)$

$=0.78+0.48(1-0.78)$

$=0.78+0.48(0.22)$

$=0.78+0.10$

$=0.88$ old 5

CFcombine $\mathrm{CF}[\mathrm{H}, \mathrm{E}] \mathrm{old} 5,7$

$=\mathrm{CF}[\mathrm{H}, \mathrm{E}]$ old $5+\mathrm{CF}[\mathrm{H}, \mathrm{E}] 7 *(1-\mathrm{CF}[\mathrm{H}, \mathrm{E}]$ old 5$)$

$=0.88+0.48(1-0.88)$

$=0.88+0.48(0.12)$

$=0.88+0.05$

$=0.93$ old 6

CFcombine $\mathrm{CF}[\mathrm{H}, \mathrm{E}] \mathrm{old} 6,8$

$=\mathrm{CF}[\mathrm{H}, \mathrm{E}]$ old $6+\mathrm{CF}[\mathrm{H}, \mathrm{E}] 8 *(1-\mathrm{CF}[\mathrm{H}, \mathrm{E}]$ old 6$)$

$=0.93+0.48(1-0.93)$

$=0.93+0.48(0.07)$

$=0.93+0.03$

$=0.96 \mathrm{old} 7$

CF[H,E]old $4 * 100=0.96 * 100=96 \%$

Dengan demikian dapat dikatakan bahwa perhitungan Certainty factor kaki gajah memiliki persentase tingat keyakinan 96\%.

\subsection{Implementasi}

Implementasi merupakan langkah yang digunakan untuk mengoperasikan sistem yang dibangun.

\subsubsection{Tampilan Menu Utama}

Tampilan menu utama digunakan untuk memilih menu dan sub menu dalam sistem. 


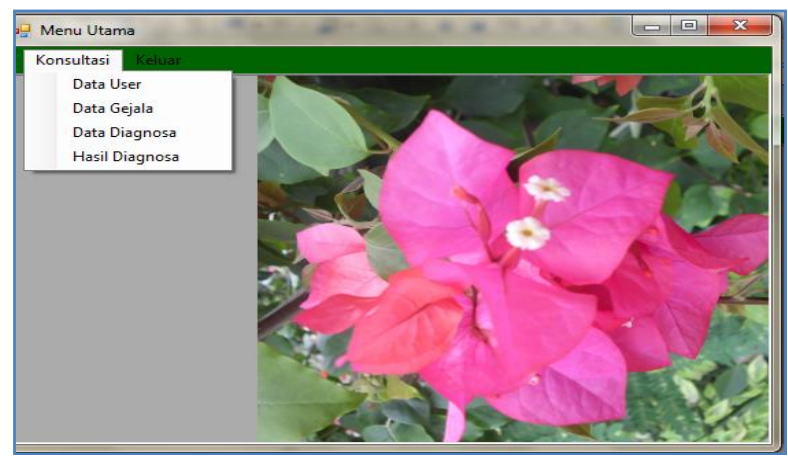

Gambar 1. Tampilan menu utama

\subsubsection{Tampilan Form Data User}

Pada tampilan form user untuk memasukan biodata seorang penderita atau pasien.

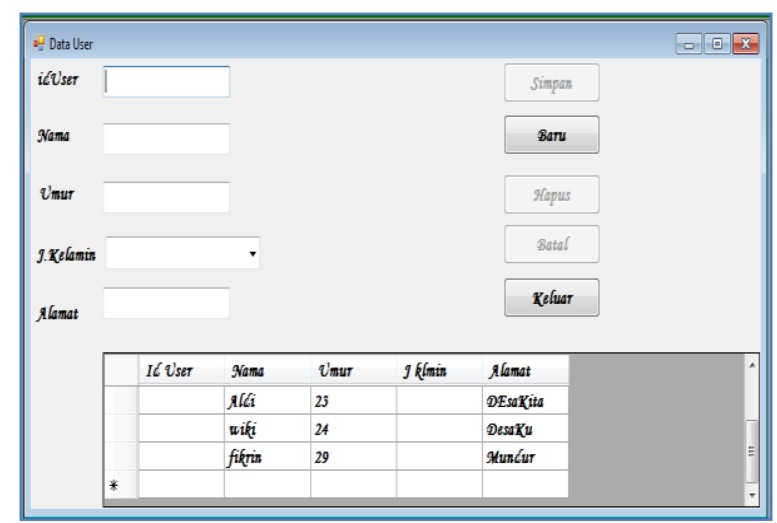

Gambar 2. Tampilan Data User

\subsubsection{Tampilan Form Data Gejala}

Pada tampilan form gejala untuk memasukan jenis-jenis gejala penyakit kaki gajah (filariasis) .

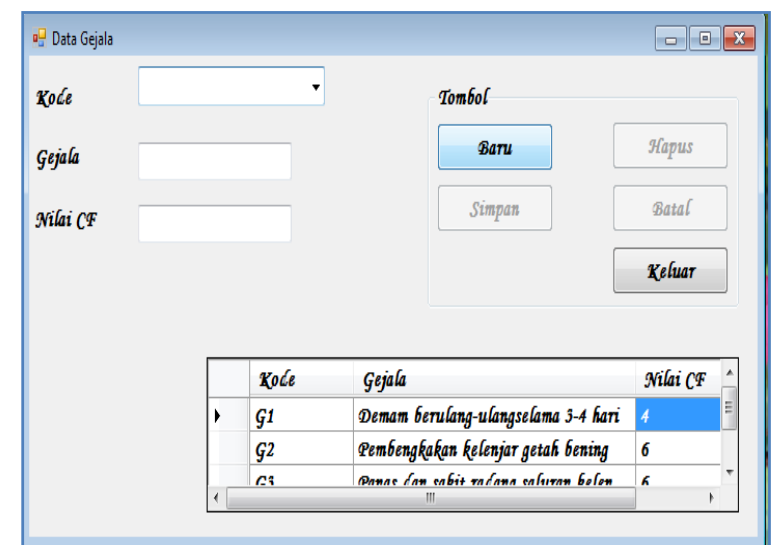

Gambar 3. Tampilan Data Gejala 


\subsubsection{Tampilan Form Diagnosa}

Menu ini digunakan untuk melakukan diagnosa berdasarkan gejala yang dirasakan oleh user. Sistem pakar akan menampilkan beberapa pertanyaan berupa dari gejala-gejala penyakit kaki gajah (filariasis) yang dapat dipilih User.

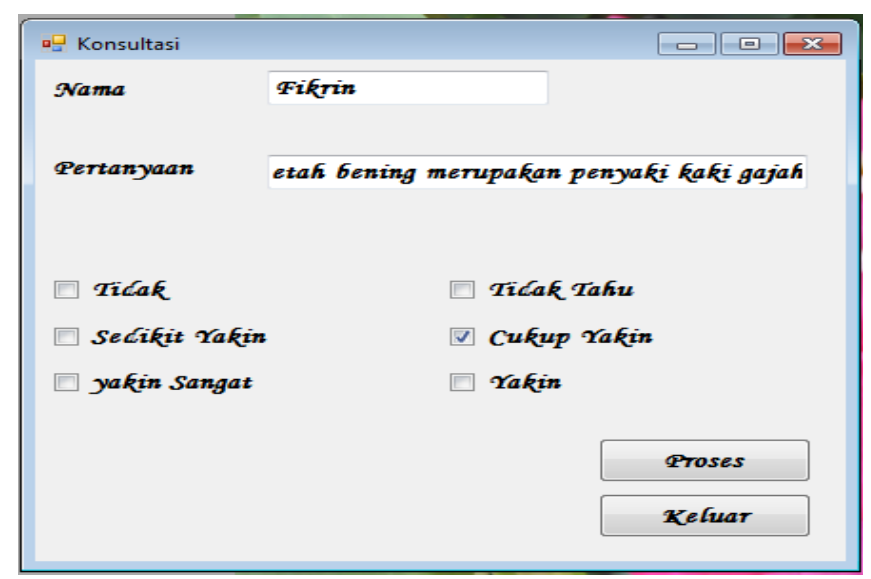

Gambar 4. Tampilan Form Diagnosa

\subsubsection{Tampilan Form Hasil Diagnosa}

Pada form hasil diagnosa user dapat melihat informasi hasil penyakit sesuai dengan hasil diagnosa berdasarkan gejala-gejala yang diderita user.

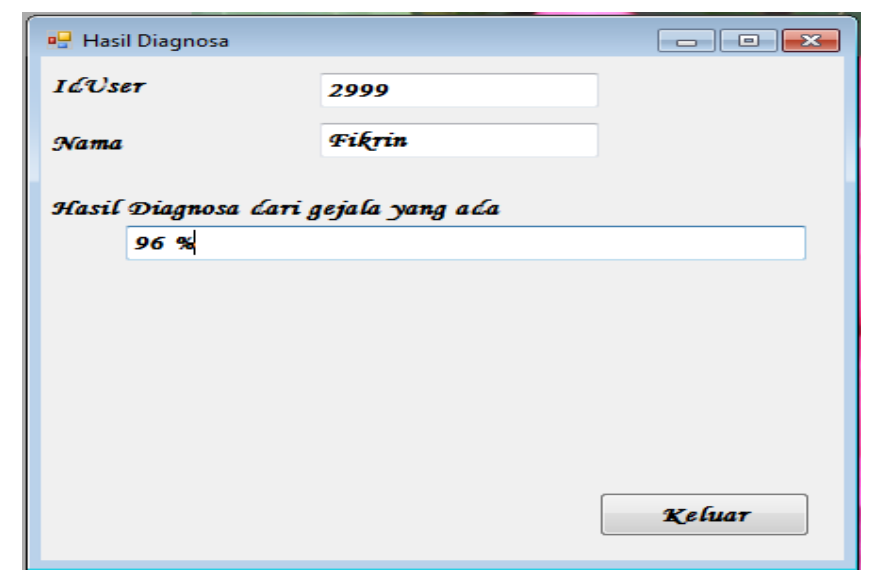

Gambar 5. Tampilan Form Hasil Diagnosa

\section{SIMPULAN}

Berdasarkan uraian pada bab sebelumnya yang merupakan hasil analisa, dapat diambil kesimpulan diantaranya :

1. Sistem pakar ini untuk menentukan penyakit kaki gajah berdasarkan gejalagejala yang ada dalam rule.

2. Penerapan metode certainty factor dalam sistem pakar untuk mendiagnosa dan mengetahui tingkat kepastian penyakit kaki gajah.

3. Aplikaasi yang dirancang dapat membantu masyarakat melakukan diagnosa sebelum konsultasi langsung kepada pakar. 


\section{DAFTAR PUSTAKA}

[1] Padila, Asuhan Keperawatan Penyakit Dalam. Yogyakarta: Nuha Medica, 2013.

[2] Verawaty Monica Barus, M. Mesran, S. Suginam, and A. Karim, "SISTEM PAKAR UNTUK MENDIAGNOSIS HAMA PADA TANAMAN JAMBU BIJI MENGGUNAKAN METODE BAYES," J. INFOTEK, vol. 2, no. 1, Feb. 2017.

[3] R. R. Fanny, N. A. Hasibuan, and E. Buulolo, "PERANCANGAN SISTEM PAKAR DIAGNOSA PENYAKIT ASIDOSIS TUBULUS RENALIS MENGGUNAKAN METODE CERTAINTY FACTOR DENGAN PENULUSURAN FORWARD CHAINING," MEDIA Inform. BUDIDARMA, vol. 1, no. 1, Feb. 2017.

[4] R. Miranda, N. A. Hasibuan, P. Pristiwanto, and M. Mesran, "SISTEM PAKAR MENDIAGNOSA PENYAKIT JAMUR AKAR PUTIH (RIQIDOPORUS LIGNOSUS) PADA TANAMAN KARET (HAVEA BRASILIENSIS) DENGAN METODE CERTAINTY FACTOR," JURIKOM (Jurnal Ris. Komputer), vol. 3, no. 6, Dec. 2016.

[5] M. Arhami, Konsep Dasar Sistem Pakar. Yogyakarta, 2005.

[6] N. Merlina and R. Hidayat, Perancangan Sistem Pakar. Bogor: Analisa Indonesia, 2013.

[7] D. A and M. Arhami, Konsep Kecerdasan Buatan. Yogyakarta, 2006.

[8] T. Sutojo and E. Mulyanto, Kecerdasan Buatan. Andi, 2010.

[9] Mesran, Visual Basic. Jakarta: Mitra Wacana Media, 2009.

[10] A. Nugroho, Rekayasa Perangkat Lunak Menggunkan UML dan Java. Yogyakarta: Andi Offset, 2009. 